\title{
FAKTOR - FAKTOR YANG MEMPENGARUHI PELAKSANAAN SELF ASSESSMENT SYSTEM WPOP JAKARTA PADA MASA PANDEMI COVID-19
}

\author{
Nimita Candraswari ${ }^{1)}$, Indra Pahala ${ }^{2)}$, Santi Susanti ${ }^{3)}$ \\ ${ }^{1,2,3}$ Universitas Negeri Jakarta \\ *Email: nimitaarin@gmail.com
}

\begin{abstract}
This study aims to analyze the effect of e-billing, taxpayer awareness, understanding of taxation and tax service services on the implementation of the Jakarta WPOP self-assessment system during the Covid-19 pandemic. This study uses primary data using a questionnaire. The population of this study is all individual taxpayers who are domiciled in DKI Jakarta. The sampling technique used is non-probability sampling with purposive sampling method. The sample used is 80 respondents. The research method used is multiple linear regression and the SPSS 26 program. The results show that e-billing has no and no significant effect on the implementation of the self-assessment system. Taxpayer awareness has no significant effect on the implementation of the self assessment system. Understanding of taxation has no effect and is significant on the implementation of the self assessment system. Fiscal services have no significant and significant effect on the implementation of the selfassessment system during the Covid-19 pandemic.
\end{abstract}

Keywords: Self Assessment System, individual taxpayer, tax awareness, e-billing, covid-19

\begin{abstract}
ABSTRAK
Penelitian ini bertujuan untuk menganalisis pengaruh e-billing, kesadaran wajib pajak, pemahaman perpajakan dan pelayanan fiskus terhadap pelaksanaan self assessment system WPOP Jakarta pada masa pandemi Covid19. Penelitian ini menggunakan data primer menggunakan kuesioner. Populasi penelitian ini adalah seluruh wajib pajak orang pribadi yang berdomisili di DKI Jakarta. Teknik pengambilan sampel yang digunakan adalah nonprobabilty sampling dengan metode purposive sampling. Sampel yang digunakan adalah 80 responden. Metode penelitian yang digunakan yakni regresi linear berganda dan program SPSS 26. Hasil penelitian menunjukkan bahwa e-billing tidak berpengaruh dan tidak signifikan terhadap pelaksanaan self assessment system. Kesadaran wajib pajak berpengaruh dan tidak signifikan terhadap pelaksanaan self assessment system. Pemahaman perpajakan tidak berpengaruh dan signifikan terhadap pelaksanaan self assessment system. Pelayanan fiskus tidak berpengaruh dan signifikan terhadap pelaksanaan self assessment system pada masa pandemi Covid-19.
\end{abstract}

Kata Kunci: Self Assessment System, Wajib Pajak Orang Pribadi, kesadaran pajak, covid-19

\section{PENDAHULUAN}

Sistem administrasi perpajakan merupakan mekanisme yang digunakan untuk menghitung besarnya pajak yang harus dibayar oleh wajib pajak kepada negara. Di Indonesia sistem administrasi perpajakan atau sistem pemungutan pajak menganut tiga jenis, salah satunya adalah self assessment system. Self assessment system merupakan sistem perpajakan yang digunakan untuk menentukan besarnya pajak yang harus dibayar oleh wajib pajak yang bersangkutan. Dengan kata lain, wajib pajak adalah pihak yang berperan aktif dalam menghitung, membayar, dan melaporkan jumlah pajak ke Kantor Pelayanan Pajak (KPP) atau melalui sistem manajemen online yang dibuat oleh pemerintah. Peran pemerintah dalam sistem perpajakan ini adalah berperan sebagai pengawas wajib pajak. Self assessment system 
berlaku untuk perpajakan pusat. Namun, sistem pemungutan dan pengelolaan pajak ini akan memiliki konsekuensi. Karena wajib pajak memiliki hak untuk menghitung sendiri jumlah pajak yang harus dibayar, maka wajib pajak biasanya berusaha membayar pajak sesedikit mungkin.

Pada tahun 2020 yang lalu berdasarkan informasi laporan tentang kinerja direktorat jendral pajak di tahun 2020 menyatakan adanya naik turunnya penerimaan pajak jika dilihat dari tahun 2016. Jika dilihat kontribusi penerimaan pajak terhadap APBN tahun 2016 dengan penerimaan sebesar 1.106 trilun dengan pertumbuhan $3.6 \%$, tahun 2017 sebesar 1.151,1 triliun dengan pertumbuhan $4.6 \%$ dan ditahun 2018 mengalami peningkatan yang signifikan sebesar 1.313,1 trilun dengan pertumbuhan $13 \%$. Namun kontribusi penerimaan pajak terhadap APBN ditahun 2019 mengalami penurunan penerimaan pajak sebesar 1.332,7 triliun dengan pertumbuhan $1.8 \%$ dan puncaknya ditahun 2020 sebesar 1.198,8 trilun dengan terkoreksi negatif sebesar $9.2 \%$.

Menurut Undang-Undang KUP yang membahas tata cara dan ketentuan perpajakan yang berlaku di Indonesia menyatakan masyarakat diberi kepercayaan penuh dalam melaksanakan kewajiban pepajakannya dengan menghitung, membayar kemudian wajib pajak dapat melaporkan teruntangnya, atau sering disebut self assessment. Dengan harapan masyarakat dapat melakukan kewajiban perpajakannnya dengan mudah dimasa pendemi Covid -19 ini, dan memberikan keringanan kepada fiskus dalam melayani wajib pajak terkait pelaksanaan kewajiban perpajakannya. Penerapan self assessment dapat kemudahan wajib pajak untuk menghitung, membayar kemudian wajib pajak melaporkan pajak terhutangnya.

Penerapan self assessment sudah ada di Indonesia sejak lama, hal ini akan berdampak pada kesadaran wajib dalam penerapan self assessment. Mengingat pentingnya perpajakan bagi negara, maka sangat perlu memiliki sikap kesadaran sebagai subjek wajib pajak dan memiliki keharusan membayar kewajiban pajaknya. Sebagai bentuk meningkatkan kesadaran wajib pajak, Direktorat Jenderal Pajak menyelenggarakan Program Insklusi dan Pendidikan tentang sadar akan pajak. Hal ini bertujuan untuk menciptakan generasi yang patuh membayar pajak (DJP, 2018 : 106) .

Terdapat beberapa faktor-faktor yang dapat mempengaruhi pelaksanaan self assessment system WPOP Jakarta pada masa pandemi Covid-19. Faktor pertama yang dapat mempengaruhi pelaksanaan self assessment system WPOP Jakarta pada masa pandemi Covid19 yaitu e-billing, Dengan menggunakan e-billing atau tagihan elektronik, wajib pajak dapat melakukan transaksi perpajakan dengan lebih cepat dan akurat. Hal ini disejalan dengan hasil 
penelitian (Widjaja \& Siagian, 2017) dan menyatakan e-billing secara signifikan berpengaruh terhadap penerapan self assessment system. Dengan adanya e-billing DJP berharap wajib pajak dimudahkan dan berperan aktif dalam melaksanakan kewajibannya yaitu menghitung, membayar dan melaporkan pajak terutang dengan menerapkan self assessment system.

Faktor kedua yang dapat mempengaruhi pelaksanaan self assessment system WPOP Jakarta pada masa pandemi Covid-19 yaitu kesadaran wajib pajak, Hal ini disejalan dengan hasil penelitian (Maulana et al., 2017) menyatakan kesadaran wajib pajak secara signifikan berpengaruh terhadap penerapan self assessment system. Mengingat pentingnya perpajakan bagi negara, maka sangat perlu memiliki kesadaran sebagai wajib pajak dan wajib pajak harus sadar membayar kewajiban pajaknya. Oleh karena itu, semakin tinggi kesadaran wajib pajak dalam membayar pajak, maka semakin tinggi pula kesadarannya untuk mematuhi kewajiban perpajakan.

Faktor ketiga yang dapat mempengaruhi pelaksanaan self assessment system WPOP Jakarta pada masa pandemi Covid-19 yaitu pemahaman perpajakan, Hal ini disejalan dengan hasil penelitian (Komang Budi Kartini et al., 2017) menyatakan pemahaman perpajakan secara signifikan berpengaruh terhadap penerapan self assessment system. Pemahaman wajib pajak terhadap peraturan perpajakan merupakan alasan internal, karena berada di bawah kendali wajib pajak.

Faktor keempat yang dapat mempengaruhi pelaksanaan self assessment system WPOP Jakarta pada masa pandemi Covid-19 yaitu pelayanan fiskus, Selama memenuhi protokol kesehatan dalam upaya menggurangi dampak Covid-19 ini, penerapan self assessment peran fiskus juga mempengaruhi. Dengan mengoptimalkan layanan kepada wajib pajak, fiskus memberikan pelayanan berkualitas dengan standar yang terpercaya, tepat waktu, konsisten dan profesional sesuai dengan peraturan yang berlaku. Salah satunya dengan mengsosialisasikan insentif perpajakan dimasa Covid -19 (DJP, 2020 : 50). Pernyataan ini sesuai dengan hasil penelitian (Awwalina Farihin Yadinta et al., 2018) dan (Erawati \& Parera, 2017) menyatakan fiskus secara signifikan berpengaruh terhadap penerapan self assessment. Agar wajib pajak dengan sikap kerelaan dan taat dan meningkatkan sikap kepatuhan wajib pajak dalam memenuhi kewajibannya, kualitas fiksus juga harus ditingkatkan.

Berdasarkan atas latar belakang masalah dan hasil dari penelitian-penelitian terdahulu yang relevan, peneliti termotivasi melakukan penelitian untuk menganalisis dan mengetahui faktor-faktor yang memengaruhi penerapan self assessment WPOP Jakara selama pandemi 
Covid-19. Maka peneliti bertujuan untuk menguji kembali terhadap unsur-unsur yang memiliki pengaruh pada Self Assessment System.

\section{TINJAUAN PUSTAKA DAN HIPOTESIS}

\section{Teori aksi Beralasan atau Theory of Reasoned Action}

Didalam penelitian yang dilakukan (Kayati, 2018), Fishbein dan Ajzen mengembangkan sebuah teori yang disebut “ teori aksi beralasan” teori ini menjelaskan bagaimana seseorang memahami perilaku orang lain berdasarkan niat orang lain itu, melalui gabung dari sikap kemauan seseorang, keyakinan seseorang dan perilaku seseorang dan dengan demikian seseorang dapat memahami perilaku orang lain.

\section{Teori Atribusi (Attribution Theory)}

Didalam penelitian yang dilakukan (Pratomo \& Achyani, 2015) Newcomb \& Heider telah mengembangkan sebuah teori yang disebut " teori atribusi", teori ini menjelaskan seseorang berupaya menilai sebab atau motivasi kejadian untuk dipromosikan perilaku seseorang.

\section{Definisi Pajak}

Didalam penelitian yang dilakukan (Sukiyaningsih, 2020), pajak adalah uran dari rakyat kepada kas negara yang dibayarkan wajib pajak pribadi ataupun badan menurut peraturan dan ketentuan perpajakan yang berlaku dan sifatnya memaksa, namun tidak secara langsung mendapatkan timbal balik

\section{E-Billing}

E-billing merupakan reformasi dari sistem pemungutan pajak. E-billing merupakan tata cara atau pembayaran elektronik lewat ATM dengan cara menginput kode billing yang akan didapat wajib pajak sebagai kode transaksi.

\section{Kesadaran Wajib Pajak}

Kesadaran wajib pajak merupakan suatu alasan terpenting untuk mendorong keinginan wajib pajak untuk mewujudkan kewajibannya sebagai wajib pajak terkait pajak terhutangnya.

\section{Pemahaman Wajib Pajak}

Pemahaman konsep atau ketentuan perpajakan dapat dilakukan dengan mengkaji ketentuan perpajakan. Wajib pajak tidak akan memahami konsep dan ketentuan perpajakan akan menjadi wajib pajak yang tidak patuh.

\section{Pelayanan Fiskus}

Pelayanan fiskus adalah perlakukan yang petugas pajak berikan kepada masyarakat yang dianggpa sebagai wajib pajak menurut peraturan perpajakan agar wajib pajak merasa nyaman, puas dan dihargai. 


\section{Pengembangan Hipotesis}

1. E-billing adalah metode pembayaran pajak terhutang menggunakan tekonlogi eletronik dengan mentertakan kode billing yang diterima wajib pajak .Oleh karena itu wajib pajak tidak perlu lagi datang kekantor pelayanan pajak untuk melakukan kewajibannya dan hal ini akan mempengaruhi pelaksanaan self assessment system WPOP Jakarta pada masa pandemi Covid-19. Hal ini disejalan dengan hasil penelitian (Widjaja \& Siagian, 2017), menyatakan $e$-billing berpengaruh terhadap penerapan self assessment. Menurut penjelasan diatas dan hasil penelitian yang mendukung, maka peneliti merumuskan jawaban sementara berupa hipotesis sebagai berikut :

$H_{1}=E$-billing berpengaruh dan positif terhadap pelaksanaan self asssessment system WPOP Jakarta Pada Masa Pandemi Covid-19

2. Diperlukan adanya sikap kerelaan yang dimiliki wajib pajak untuk memenuhi kewajibannya dan kesediaan wajib pajak untuk mematuhi peraturan yang berlaku dan akan mempengaruhi pelaksanaan self assessment system WPOP Jakarta pada masa pandemi Covid-19. Pernyataan ini sesuai dengan hasil penelitian (Maulana et al., 2017), menyatakan kesadaran wajib pajak berpengaruh terhadap penerapan self assessment. Menurut penjelasan diatas dan hasil penelitian yang mendukung, maka peneliti merumuskan jawaban sementara berupa hipotesis sebagai berikut :

\section{$\mathrm{H}_{2}=$ Kesadaran wajib pajak berpengaruh dan positif terhadap pelaksanaan self assessment WPOP Jakarta Pada Masa Pandemi Covid-19}

3. Wajib pajak tidak akan memahami konsep dan ketentuan perpajakan yang berlaku akan cenderung menjadi wajib pajak yang tidak patuh. Jadi dapat disimpulkan semakin wajib pajak memahami peraturan perpajakan, maka semakin paham pula wajib pajak terhadap sanksi yang akan diterima sehubung dengan kewajiban perpajakannya dan pemahaman perpajakan yang dimiliki wajib pajak akan mempengaruhi pelaksanaan self assessment system WPOP Jakarta pada masa pandemi Covid-19. Pernyataan ini sesuai dengan hasil penelitian (Nayoan et al., 2016), menyatakan pemahaman perpajakan berpengaruh terhadap penerapan self assessment. Menurut penjelasan diatas dan hasil penelitian yang mendukung, maka peneliti merumuskan jawaban sementara berupa hipotesis sebagai berikut :

\section{$\mathrm{H}_{3}=$ Pemahaman perpajakan berpengaruh dan positif terhadap pelaksanaan self asssessment system WPOP Jakarta Pada Masa Pandemi Covid-19}


4. Perilaku yang mengimplementasikan teori ini adalah tingkah laku yang ditunjukan fiskus (petugas pajak) ketika melayani wajib pajak yang datang kekantor pelayanan pajak memiliki niatan mendapatkan kesan baik akan mempengaruhi pelaksanaan self assessment system WPOP Jakarta pada masa pandemi Covid-19. Pernyataan ini sesuai dengan hasil penelitian (Maulana et al., 2017), (N. E. Putri \& Pharamitha, 2018), menyatakan pelayanan fiskus secara signifikan berpengaruh terhadap penerapan self assessment. Menurut penjelasan diatas dan hasil penelitian yang mendukung, maka peneliti merumuskan jawaban sementara berupa hipotesis sebagai berikut :

\section{$H_{4}=$ Pelayanan fiskus berpengaruh dan positif terhadap pelaksanaan self asssessment system WPOP Jakarta Pada Masa Pandemi Covid-19}

\section{METODE PENELITIAN}

Populasi penelitian ini adalah Wajib Pajak Orang Pribadi berdomisili di Jakarta tahun 2021. Menurut data pada (Lakin DJP,2020) bahwa jumlah WPOP DKI Jakarta sebanyak 159.758. Pengambilan sampel menggunakan teknik purposive sampling yang merupakan nonprobability sampling.

Sampel penelitian ini wajib pajak orang pribadi yang berdasarkan pertimbangan tertentu dan tidak menyimpang dari ciri-ciri atau kriteria sampel yang telah ditetapkan. Untuk menyeleksi kembali sampel yang sesuai dan mewakili sampel penelitian ini adalah menggunakan pendapat Roscoe didalam (Slamet, 2020), yang mengatakan bahwa dalam menentukan sampel yang mewakili sampel dari populasi dalam model analisis regresi berganda atau sebuah penelitian multivariare, jumlah atau banyakanya ukuran sampel dianjurkan 10 kali dari jumlah variabel yang digunakan, Namun, dalam menghindari ketidakpastian dan ketidakrelavan data, untuk itu penulis menambah 30 sampel yang sudah ditentukan menjadi 80 sampel. Penelitian ini menggunakan data primer sebagai bahan penelitian yang akan diolah.

Dalam penelitian ini data yang digunakan berupa data primer yang langsung diperoleh peneliti melalui menyebar kuesioner menggunakan google forms atau online, yang berisi banyak pertanyaan terstruktur. Minta orang yang wawancara menjawab setiap pertanyaan kuesioner berdasarkan situasi orang yang diwawancarai. Karena peneliti menggunakan beberapa variabel bebas maka teknik analisis adalah persamaan regresi linier berganda. Untuk dapat menjawab pertanyaan penelitian, peneliti menggunakan desain penelitian kausal kompraratif. 


\section{HASIL DAN PEMBAHASAN}

\section{Analisis Statistik Deskriptif}

Analisis statistik deskriptif menyajikan interpretasi data yang diperoleh melalui jumlah maksimum, minimum, mean, standar deviasi dan varians yang dapat digunakan untuk menganalisis data. Oleh karena itu, statistik deskriptif semacam ini bertujuan untuk mendeskripsikan data yang telah diperoleh tanpa menarik kesimpulan secara umum (Putri et al., 2019).

Data penelitian yang dimaksud adalah variabel independen, meliputi e-billling $\left(\mathrm{X}_{1}\right)$, kesadaran wajib pajak $\left(\mathrm{X}_{2}\right)$, pemahaman perpajakan $\left(\mathrm{X}_{3}\right)$, dan pelayanan fiskus $\left(\mathrm{X}_{4}\right)$ dan variabel dependen yaitu Self Assessment (Y). Berikut tabel hasil analisis statistik deskriptif:

Tabel I. Hasil Analisis Statistik Deskriptif

\begin{tabular}{|l|c|c|c|c|c|c|}
\hline & $\mathbf{N}$ & \multicolumn{5}{|c|}{ Statistik Deskriptif } \\
& & $\begin{array}{c}\text { Mini } \\
\text { mum }\end{array}$ & $\begin{array}{c}\text { Maksi } \\
\text { mum }\end{array}$ & Mean & $\begin{array}{c}\text { St. } \\
\text { Dev }\end{array}$ & $\begin{array}{c}\text { Vari } \\
\text { ance }\end{array}$ \\
\hline E-Billing & 80 & 19 & 40 & 29,29 & 4,696 & 22,056 \\
\hline Kesadaran Wajib Pajak & 80 & 14 & 40 & 24,86 & 5,405 & 29,209 \\
\hline Pemahaman Perpajakan & 80 & 14 & 41 & 27,14 & 7,103 & 50,449 \\
\hline Pelayanan Fiskus & 80 & 21 & 41 & 30,73 & 4,383 & 19,215 \\
\hline Self Assessment & 80 & 13 & 36 & 24,66 & 5,634 & 31,745 \\
\hline Valid N (listwise) & & & & & & \\
\hline
\end{tabular}

Sumber: diolah oleh penulis, 2021

Berdasarkan tabel I. diatas hasil analisis statistk deskriptif dapat ditarik kesimpulan dengan masing-masing variabel yang digunakan dan berikut penjelasannya:

\section{1) E-Billing $\left(\mathrm{X}_{1}\right)$}

Variabel independen pertama dalam penelitian ini menggunakan e-billing yang diukur dengan menggunakan kuesioner dengan jumlah 80 responden. Berdasarkan tabel IV. 6 diatas hasil analisis statistk deskriptif variabel e-billing memiliki nilai minimum 19, nilai maksimum 40, nilai mean 29.29, nilai standar devasi 4.696 dan nilai variance 22.056 .

\section{2) Kesadaran Wajib Pajak $\left(\mathbf{X}_{2}\right)$}

Variabel independen kedua dalam penelitian ini menggunakan kesadaran wajib pajak yang diukur dengan menggunakan kuesioner dengan jumlah 80 responden. Berdasarkan tabel IV. 6 diatas hasil analisis statistk deskriptif variabel kesadaran wajib pajak memiliki 
nilai minimum 14, nilai maksimum 40, nilai mean 24.86, nilai standar devasi 5.405 dan nilai variance 29.209.

\section{3) Pemahaman Perpajakan $\left(\mathbf{X}_{3}\right)$}

Variabel independen ketiga dalam penelitian ini menggunakan pemahaman perpajakan yang diukur dengan menggunakan kuesioner dengan jumlah 80 responden. Berdasarkan tabel IV. 6 diatas hasil analisis statistk deskriptif variabel pemahaman perpajakan memiliki nilai minimum 14 , nilai maksimum 41, nilai mean 27.14 , nilai standar devasi 7.103 dan nilai variance 50.449 .

\section{4) Pelayanan Fiskus $\left(\mathbf{X}_{4}\right)$}

Variabel independen keempat dalam penelitian ini menggunakan pelayanan fiskus yang diukur dengan menggunakan kuesioner dengan jumlah 80 responden. Berdasarkan tabel IV. 6 diatas hasil analisis statistk deskriptif variabel pelayanan fiskus memiliki nilai minimum 21, nilai maksimum 41, nilai mean 30.73, nilai standar devasi 4.383 dan nilai variance 19.215 .

\section{5) Self Assessment System (Y)}

Berdasarkan hasil analisis desktiptif dapat ditarik penjelasan bahwa pelaksanaan self assessment system WPOP Jakarta pada masa pandemi covid-19, dimana variabel self assessment system menggambarkan memiliki nilai data minimum 5, nilai maksimum 13, nilai mean 9.37, nilai standar devasi 2.153 dan nilai variance 4.658 .

\section{Hasil Penelitian}

\section{Hasil Uji Validitas}

Hasil uji validitas menunjukkan E-Billing, Kesadaran wajib pajak, pemahaman perpajakan, kualitas pelayanan fiskus dan self assessment system memiliki hasil uji validitas data dengan nilai rhitung (lebih besar dari) nilai rtabel $=0.1852$, maka dapat disimpulkan kalau butir pertanyaan atau indikator tersebut dinyatakan valid.

\section{Uji Reabilitas Data}

Tabel II. Hasil Uji Reabilitas Data

\begin{tabular}{|l|l|l|l|}
\hline Variabel & $\mathbf{N}$ & $\begin{array}{l}\text { Cronbach' } \\
\text { s Alpha }\end{array}$ & Keterangan \\
\hline E-billing & 80 & 0.781 & Reliabel \\
\hline Kesadaran Wajib Pajak & 80 & 0.724 & Reliabel \\
\hline Pemahaman Perpajakan & 80 & 0.844 & Reliabel \\
\hline Pelayanan Fiskus & 80 & 0.814 & Reliabed \\
\hline Self Assesment System & 80 & 0.767 & Reliabel \\
\hline
\end{tabular}


Sumber: diolah oleh penulis, 2021

Tabel II. menunjukkan E-Billing, Kesadaran wajib pajak, pemahaman perpajakan, kualitas pelayanan fiskus dan self assessment system memiliki hasil uji reabilitas memiliki nilai cronbach's alpha lebih besar dari 0.600 sebesar (cronbach's alpha) > (0.600), artinya data reliabel.

\section{Uji Asumsi Klasik}

1) Hasil Uji Normalitas

\section{Gambar I. Hasil Uji Normalitas P-P Plot}

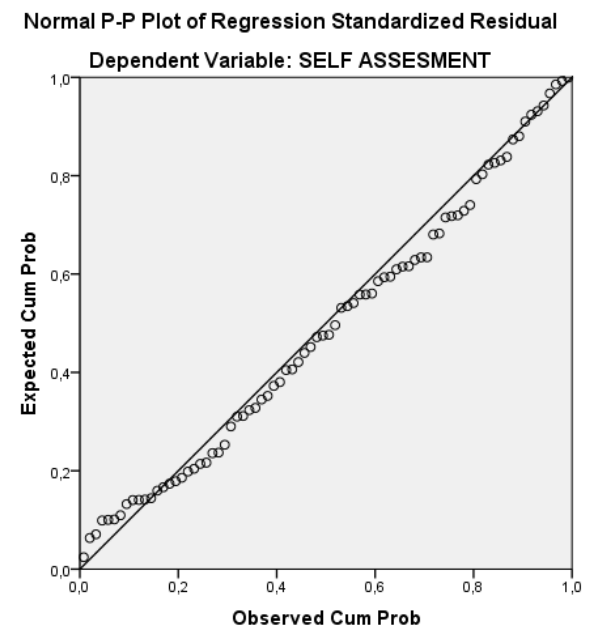

Sumber: diolah oleh penulis, 2021

Gambar I. Menunjukkan hasil uji normalitas PP-Plot bahwa data berdistribusi dengan normal karena terlihat titik - titik menyebar di sekitar garis diagonal dan penyebarannya mengikuti arah garis diagonalnya.

2) Hasil Uji Multikolinearitas

Tabel III. Hasil Uji multikolinieritas

\begin{tabular}{|c|c|c|c|c|c|c|c|}
\hline \multirow[t]{2}{*}{ Model } & \multicolumn{2}{|c|}{$\begin{array}{l}\text { Unstandardized } \\
\text { Coefficients }\end{array}$} & \multirow{2}{*}{$\begin{array}{l}\text { Standardize } \\
d \\
\text { Coefficients } \\
\text { Beta }\end{array}$} & \multirow[b]{2}{*}{$t$} & \multirow[b]{2}{*}{ Sig } & \multicolumn{2}{|c|}{ Collinearity Statistics } \\
\hline & $B$ & $\begin{array}{l}\text { Std. } \\
\text { Error }\end{array}$ & & & & Tolerance & VIF \\
\hline (Constant) & 3.220 & 5.824 & & 0.553 & 0.582 & & \\
\hline E-Billing & 0.056 & 0.103 & 0.056 & 0.539 & 0.591 & 0.903 & 1.107 \\
\hline $\begin{array}{l}\text { Kesadaran } \\
\text { Wajib Pajak }\end{array}$ & 0.395 & 0.106 & 0.379 & 3.730 & 0.000 & 0.959 & 1.043 \\
\hline $\begin{array}{l}\text { Pemahaman } \\
\text { Perpajakan }\end{array}$ & 0.288 & 0.086 & 0,363 & 3.353 & 0.001 & 0.845 & 1.184 \\
\hline $\begin{array}{l}\text { Pelayanan } \\
\text { Fiskus }\end{array}$ & 0.062 & 0.108 & 0.062 & 0.576 & 0.566 & 0.860 & 1.163 \\
\hline
\end{tabular}


Sumber : diolah oleh penulis, 2021

Tabel III. menunjukkan E-Billing, Kesadaran wajib pajak, pemahaman perpajakan, kualitas pelayanan fiskus dan self assessment system memiliki hasil uji multikolinieritas memiliki nilai memiliki nilai toleransi memiliki nilai toleransi > $(0.10)$ dan nilai $\mathrm{VIF}<(10)$, artinya tidak ada terjadinya multikolinieritas data.

3) Hasil Uji Heteroskedastisitas

\section{Gambar II. Hasil Uji Heteroskedastisitas Scatterplot}

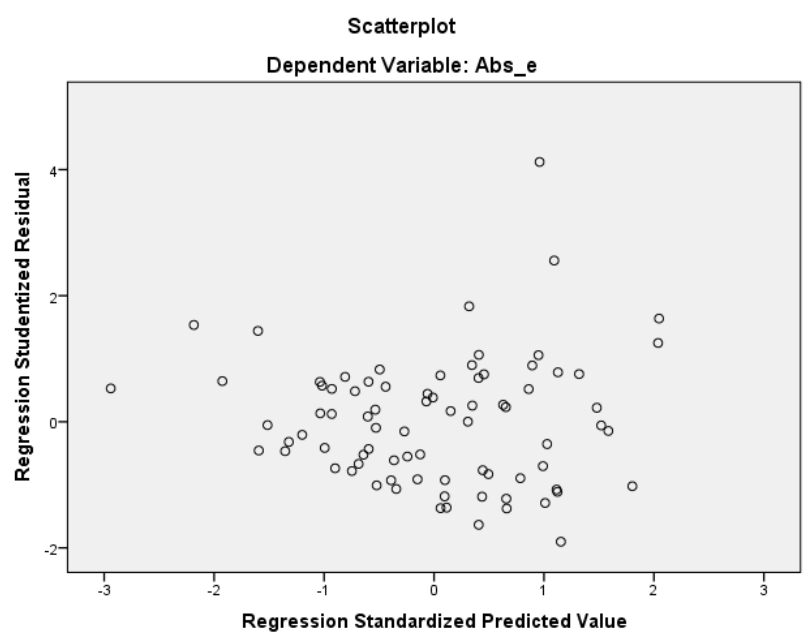

Sumber: diolah oleh penulis, 2021

Gambar II. Menunjukkan dasar hasil uji heteroskedastisitas scatterplot bahwa tidak adanya gejala heteroskedastisitas karena terlihat bahwa jika pola tertentu tidak terbentuk dan titik-titiknya tersebar diatas dan dibawah sumbuh y dan angka 0 ,

\section{Uji Regresi Linier Berganda}

Analisis regresi linier berganda adalah analisis regresi statistik yang digunakan untuk mengetahui nilai rata-rata variabel dependen yang dipengaruhi variabel independen (Agustiningsih, 2016). Berikut tabel hasil analisis regresi linier berganda menggunakan SPSS 24, sebagai berikut:

Tabel IV. Hasil Uji Regresi Linier Berganda

\begin{tabular}{|l|l|l|l|l|l|l|}
\hline Coefficients $^{\mathrm{a}}$ & & \multicolumn{2}{l|}{$\begin{array}{l}\text { Unstandardized } \\
\text { Coefficients }\end{array}$} & $\begin{array}{l}\text { Standardi } \\
\text { zed } \\
\text { Coefficie } \\
\text { nts }\end{array}$ & T & Sig \\
\hline & & B & Std. Error & Beta & & \\
\hline & (Constant) & 3.220 & 5.824 & & 0.553 & 0.582 \\
\hline & E-Billing & 0.056 & 0.103 & 0.056 & 0.539 & 0.591 \\
\hline
\end{tabular}




\begin{tabular}{|l|l|l|l|l|l|l|}
\hline & $\begin{array}{l}\text { Kesadaran } \\
\text { Wajib Pajak }\end{array}$ & 0.395 & 0.106 & 0.379 & 3.730 & 0.000 \\
\hline & $\begin{array}{l}\text { Pemahaman } \\
\text { Perpajakan }\end{array}$ & 0.288 & 0.086 & 0,363 & 3.353 & 0.001 \\
\hline & $\begin{array}{l}\text { Pelayanan } \\
\text { Fiskus }\end{array}$ & 0.062 & 0.108 & 0.062 & 0.576 & 0.566 \\
\hline
\end{tabular}

Sumber : diolah oleh penulis, 2021

Berdasarkan tabel IV. hasil penelitian uji regresi linier berganda menunjukan persamaan linier sebagai berikut :

$$
\mathrm{SA}=-0.390+0.097(\mathrm{~B})+0.369(\mathrm{~K})-0.11(\mathrm{P})-0.058(\mathrm{~F})+\mathrm{e}
$$

Keterangan:

$$
\begin{array}{ll}
\text { SA } & =\text { Self Assessment System } \\
\alpha & =\text { Konstanta } \\
\beta_{1}-\beta_{4} & =\text { Koefisien variabel independen } \\
B & =\text { e-billing, } \\
K & =\text { kesadaran wajib pajak, } \\
P & =\text { pemahaman perpajakan } \\
F & =\text { pelayanan fiskus } \\
e & =\text { error }
\end{array}
$$

Tabel IV. menunjukkan hasil uji analisis regresi linier berganda dapat ditarik kesimpulan bahwa pelaksanaan self assessment system WPOP Jakarta pada masa pandemi covid-19 yang dipengaruhi oleh e-billing, kesadaran wajib pajak, pemahaman perpajakan dan pelayanan fiskus memiliki nilai positif konstanta sebesar (0.056), (0.395), (0.288), (0.062) artinya semakin naiknya satu pelaksanaan self assessment system WPOP Jakarta pada masa pandemi covid-19 yang dipengaruhi oleh e-billing, kesadaran wajib pajak, pemahaman perpajakan dan pelayanan fiskus diimbangi dengan nilai konstanta sebesar (0.056), (0.395), (0.288), (0.062)

\section{Uji Hipotesis}

1) Koefisien Determinasi $R^{2}$

Berikut gambar hasil uji koefisien determinasi, sebaga berikut : 
Tabel VI. Hasil Uji Koefisien Determinasi $\mathbf{R}^{2}$

\begin{tabular}{|l|l|l|l|l|}
\hline \multicolumn{5}{|c|}{ Model Summary } \\
\hline Model & R & R Suare & $\begin{array}{l}\text { Adjusted R } \\
\text { Square }\end{array}$ & Std. Error of the Estimate \\
\hline $\mathbf{l}$ &, $509^{\mathrm{a}}$ &, 259 &, 219 & 4,97905 \\
\hline $\begin{array}{l}\text { a. Predictors: (Constant), Pelayanan Fiskus, Pemahaman Perpajakan, } \\
\text { Kesadaran Wajib Pajak, E-Billing }\end{array}$ \\
\hline \multicolumn{4}{|l|}{ b. Dependent Variable: Self Assesment } \\
\hline \multicolumn{4}{|l}{} \\
\hline
\end{tabular}

Sumber: diolah oleh penulis, 2021

Tabel VI. hasil penelitian uji koefisien determinasi $\mathrm{R}^{2}$ menunjukan nilai Adjusted $R$ Square $(0,259)$, artinya kemampuan variabel independen dalam mempengaruhi variabel dependen penelitian ini adalah $21.9 \%$. Maka dapat ditarik kesimpulan bahwa pelaksanaan self assessment system WPOP Jakarta pada masa pandemi covid-19 yang dipengaruhi oleh e-billing, kesadaran wajib pajak, pemahaman perpajakan dan pelayanan fiskus memiliki kemampuan sebesar $21.9 \%$.

2) Hasil Uji t

Berikut tabel hasil uji t, sebagai berikut:

\section{Tabel VII. Hasil Uji T}

\begin{tabular}{|l|l|l|l|l|l|}
\hline \multirow{2}{*}{ Model } & \multicolumn{2}{|l|}{$\begin{array}{l}\text { Unstandardized } \\
\text { Coefficients }\end{array}$} & $\begin{array}{l}\text { Standar } \\
\text { dized } \\
\text { Coeffici } \\
\text { ents }\end{array}$ & \multicolumn{2}{l|}{} \\
\cline { 2 - 6 } & $B$ & $\begin{array}{l}\text { Std. } \\
\text { Error }\end{array}$ & Beta & $t$ & Sig \\
\hline (Constant) & 3.220 & 5.824 & & 0.553 & 0.582 \\
\hline E-Billing & 0.056 & 0.103 & 0.056 & 0.539 & 0.591 \\
\hline $\begin{array}{l}\text { Kesadaran Wajib } \\
\text { Pajak }\end{array}$ & 0.395 & 0.106 & 0.379 & 3.730 & 0.000 \\
\hline $\begin{array}{l}\text { Pemahaman } \\
\text { Perpajakan }\end{array}$ & 0.288 & 0.086 & 0,363 & 3.353 & 0.001 \\
\hline Pelayanan Fiskus & 0.062 & 0.108 & 0.062 & 0.576 & 0.566 \\
\hline a. Dependent Variable: Self Assesment & & & & \\
\hline
\end{tabular}

Sumber : diolah oleh penulis, 2021

Tabel VII. hasil penelitian uji t menunjukan nilai sig variabel e-billing (0.591), kesadaran wajib pajak (0.000), pemahaman perpajakan (0.001) dan pelayanan fiskus (0.566). 
Jumlah responden yang digunakan dalam penelitian ini adalah 80 responden, maka berati untuk menentukan Ttabel menggunakan $\mathrm{df}=\mathrm{n}=\mathrm{k}-1$ dengan signifikansi 5\% Ttabel. Diketahui $\mathrm{df}=80-4-1=75$, yang artinya $(\mathrm{n})$ merupakan jumlah sampel yang digunakan dalam penelitian, (k) merupakan banyaknya variabel independen yang digunakand alam penelitian ini dan dikurangi satu (1). Dari hasil Ttabel, diketahui $\mathrm{df}=75$ dengan nilai Ttabel dengan signifikansi 5\% sebesar $=(1.992)$

1) E-Billing Tidak Berpengaruh Signifikan Terhadap Pelaksanaan Self Assessment System WPOP Jakarta Pada Masa Pandemi Covid-19

Berdasarkan tabel IV.11 hasil penelitian uji $\mathrm{t}$ menunjukan bahwa pelaksanaan self assessment system WPOP Jakarta pada masa pandemi covid-19 yang dipengaruhi secara parsial oleh e-billing memiliki nilai signifikansi (0.591) dan Thitung (0.539), artinya e-billing tidak berpengaruh signifikan terhadap pelaksanaan self assessment system WPOP Jakarta pada masa pandemi Covid-19, karena nilai signifikansi (0.591) lebih besar dari (0.05) dan diketahui Thitung (0.539) kurang dari Ttabel (1.992). Hasil dari Thitung (0.539) menggambarkan nilai t menunjukan korelasi yang positif. Oleh karena itu dari hasil uji t (parsial) menyimpulkan e-billing tidak berpengaruh signifikan terhadap pelaksanaan self assessment system WPOP Jakarta pada masa pandemi Covid-19. Hal ini tidak sejalan dengan hasil penelitian (Sukiyaningsih, 2020) yang menyatakan e-billing berpengaruh signifikan dalam pelaksanaan self assessment system untuk meningkatkan kepatuhan wajib pajak.

2) Kesadaran Wajib Pajak Berpengaruh SignifikanTerhadap Pelaksanaan Self Assessment System WPOP Jakarta Pada Masa Pandemi Covid-19

Berdasarkan tabel IV.11 hasil penelitian uji t menunjukan bahwa pelaksanaan self assessment system WPOP Jakarta pada masa pandemi covid-19 yang dipengaruhi secara parsial oleh kesadaran wajib pajak memiliki nilai signifikansi (0.000) dan Thitung (3.730), artinya kesadaran wajib pajak berpengaruh signifikan terhadap pelaksanaan self assessment system WPOP Jakarta pada masa pandemi Covid-19, karena nilai signifikansi (0.000) lebih kecil dari (0.05) dan diketahui Thitung (3.730) lebih dari Ttabel (1.992). Hasil dari Thitung (3.730) menggambarkan nilai t menunjukan korelasi yang positif. Oleh karena itu dari hasil uji $\mathrm{t}$ (parsial) menyimpulkan kesadaran wajib pajak berpengaruh signifikan terhadap pelaksanaan self assessment system WPOP 
Jakarta pada masa pandemi Covid-19. Hal ini sejalan dengan penelitian (Ariesta \& Latifah, 2017) yang menyatakan kesadaran wajib pajak dalam pelaksanaan self assessment system akan mempengaruhi kepatuhan wajib pajak.

\section{3) Pemahaman Perpajakan Berpengaruh Signifikan Terhadap Pelaksanaan Self} Assessment System WPOP Jakarta Pada Masa Pandemi Covid-19

Berdasarkan tabel IV.11 hasil penelitian uji t menunjukan bahwa pelaksanaan self assessment system WPOP Jakarta pada masa pandemi covid-19 yang dipengaruhi secara parsial oleh pemahaman perpajakan memiliki nilai signifikansi (0.001) dan Thitung (3.353), artinya pemahaman perpajakan berpengaruh signifikan terhadap pelaksanaan self assessment system WPOP Jakarta pada masa pandemi Covid-19, karena nilai signifikansi (0.001) lebih kecil dari (0.05) dan diketahui Thitung (3.353) lebih dari Ttabel (1.992). Hasil dari Thitung (3.353) menggambarkan nilai t menunjukan korelasi yang positif. Oleh karena itu dari hasil uji t (parsial) menyimpulkan pemahaman perpajakan berpengaruh signifikan terhadap pelaksanaan self assessment system WPOP Jakarta pada masa pandemi Covid-19. Hal ini sejalan dengan penelitian (Nayoan et $a l .$, 2016) yang menyatakan pemahaman perpajakan dalam pelaksanaan self assessment system akan mempengaruhi kepatuhan wajib pajak dan diperkuat dengan realisasi penerimaan pajak tahun 2020 yang tertuang didalam Laporan Kinerja Direktorat Jenderal Pajak Tahun 2020.

\section{4) Pelayanan Fiskus Tidak Berpengaruh Signifikan Terhadap Pelaksanaan Self} Assessment System WPOP Jakarta Pada Masa Pandemi Covid-19

Berdasarkan tabel IV.11 hasil penelitian uji $\mathrm{t}$ menunjukan bahwa pelaksanaan self assessment system WPOP Jakarta pada masa pandemi covid-19 yang dipengaruhi secara parsial oleh pelayanan fiskus memiliki nilai signifikansi (0.556) dan Thitung (0.576), artinya pelayanan fiskus tidak berpengaruh signifikan terhadap pelaksanaan self assessment system WPOP Jakarta pada masa pandemi Covid-19, karena nilai signifikansi (0.556) lebih besar dari (0.05) dan diketahui Thitung (0.576) kurang dari Ttabel (1.992). Hasil dari Thitung (0.576) menggambarkan nilai t menunjukan korelasi yang positif. Oleh karena itu dari hasil uji t (parsial) menyimpulkan tidak berpengaruh signifikan terhadap pelaksanaan self assessment system WPOP Jakarta pada masa pandemi Covid-19. Hal ini tidak sejalan dengan hasil penalitian (Awwalina Farihin Yadinta et al., 
2018) dan (Maulana et al., 2017), yang menyatakan pelayanan fiskus dalam pelaksanaan self assessment system mempengaruhi kepatuhan wajib pajak dan diperkuat dengan realisasi penerimaan pajak tahun 2020 .

\section{PENUTUP}

Berdasarkan hasil dan pembahasan tentang pengaruh pelaksanaan self assessment system WPOP Jakarta pada masa pandemi covid-19 terhadap e-billing, kesadaran wajib pajak, pemahaman perpajakan dan pelayanan fiskus yang menggunakan 80 responden WPOP Jakarta sebagai berikut :

1) E-billing tidak berpengaruh signifikan terhadap pelaksanaan self asssessment system WPOP Jakarta Pada Masa Pandemi Covid-19

2) Kesadaran wajib pajak berpengaruh signifikan terhadap pelaksanaan self assessment system WPOP Jakarta Pada Masa Pandemi Covid-19.

3) Pemahaman perpajakan berpengaruh signifikan terhadap pelaksanaan self assessment system WPOP Jakarta Pada Masa Pandemi Covid-19.

4) Pelayanan fiskus tidak berpengaruh signifikan terhadap pelaksanaan self assessment system WPOP Jakarta Pada Masa Pandemi Covid-19.

\section{DAFTAR PUSTAKA}

Agustiningsih, W. (2016). Jurnal Nominal / Volume V Nomor 2 / Tahun 2016 Pengaruh Penerapan e-filling, Tingkat Pemahaman Perpajakan Nominal, V(4), 107-122.

Awwalina Farihin Yadinta, P., Suratno, S., \& Mulyadi, J. M. . (2018). Kualitas Pelayanan Fiskus, Dimensi Keadilan, Kesadaran Wajib Pajak dan Kepatuhan Wajib Pajak Orang Pribadi. Jurnal Riset Akuntansi \& Perpajakan (JRAP), 5(02), 201-212. https://doi.org/10.35838/jrap.v5i02.186

DJP, L. (2018). Lakin djp.

DJP, L. (2020). Laporan kinerja direktorat jenderal pajak 2020.

Erawati, T., \& Parera, A. M. W. (2017). Pengaruh Kesadaran Wajib Pajak, Sanksi Perpajakan, Pengetahuan Perpajakan, Dan Pelayanan Fiskus. Jurnal Akuntansi, 5(1), 37. https://doi.org/10.24964/ja.v5i1.255

Kayati, K. (2018). Peran Theory of Reasoned Action Terhadap MinatT Menggunakan Produk Bagi Hasil Bank Syariah. Accounthink: Journal of Accounting and Finance, 3(01), 454 467. https://doi.org/10.35706/acc.v3i01.1210

Maulana, R., P, D. P., \& Andini, R. (2017). Pengaruh Kesadaran Wajib Pajak, Sosialisasi 
Sistem Perpajakan, dan Pelayanan Kantor Pajak Terhadap Penerapan Self Assesment System Yang Berdampak Pada Kepatuhan Wajib Pajak Pelaku Social Commerce. 1-16.

Oki Sri Hartini, D. (2018). Pengaruh Pengetahuan Perpajakan dan Kesadaran Wajib Pajak Terhadap Kepatuhan Wajib Pajak Orang Pribadi. Sains Manajemen Dan Akuntansi, $10(2), 43-56$.

Pratomo, R. S., \& Achyani, D. F. (2015). Pengaruh Pengalaman Kerja, Independensi, Obyektifitas, Integritas, Kompetensi dan Akuntabilitas Terhadap Kualitas Hasil Audit (Studi Empiris pada Kantor Inspektorat Kota/Kabupaten Subosukowonosraten). E-Jurnal Akuntansi, 10-29.

Putri, T., Saerang, D. P. E., \& Budiarso, N. S. (2019). Analisis Perilaku Wajib Pajak Umkm Terhadap Pelaksanaan Pemungutan Pajak Dengan Menggunakan Self Assessment System Di Kota Tomohon. Going Concern: Jurnal Riset Akuntansi, 14(1), 130-136. https://doi.org/10.32400/gc.14.1.22321.2019

Slamet, R. dan A. H. (2020). Metode Riset Penelitian Kuantitatif Penelitian Di Bidang Manajemen, Teknik, Pendidikan Dan Eksperimen. CV Budi Utama.

Sukiyaningsih, T. W. (2020). Studi Penerapan E-System Dan Pelaksanaan Self Assesment System Terhadap Kepatuhan Wajib Pajak. 17(01), 61-72. 